\title{
Pino ósseo homólogo conservado em glicerina a $98 \%$ e hemicerclagem com fio poliglactina 910 na osteossíntese umeral de pombos domésticos
}

\author{
Homologous bone pin conserved in glycerin at $98 \%$ and hemicerclagem with a thread \\ of poliglactina 910 in humerus osteosyntesis of domestic pigeons
}

\author{
Juliano Bolson ${ }^{\text {I }}$ João Eduardo Wallau Schossler ${ }^{\text {II }}$ Gustavo Machado ${ }^{\text {III }}$ \\ Fernanda Boligon Zembrzuski ${ }^{\text {III }}$
}

RESUMO

O objetivo do presente estudo foi avaliar a utilização de um pino intramedular ósseo homólogo, conservado em glicerina a 98\%, associado à hemicerclagem com fio poliglactina 910 na osteossíntese umeral transversa de pombos domésticos (Columba livia). Utilizou-se como pino ósseo a parte distal do tibiotarso, conservado com medula óssea. Foram operados 20 pombos domésticos, adultos, nãosexados e clinicamente sadios. Esses animais foram separados ao acaso em cinco grupos, com quatro indivíduos. O úmero foi seccionado cirurgicamente na sua diáfise, de forma transversa, e o pino ósseo foi devidamente implantado no seio do osso. Orifícios foram realizados e por eles procedeu-se hemicerclagem do tipo pontos de Wolff com poliglactina 910. Os animais foram avaliados clinicamente, por meio de radiografias semanais, e histologicamente após os períodos de 15, 30, 60, 90 e 120 dias. A conservação do pino ósseo em glicerina a 98\% foi avaliada por meio de exames microbiológicos. Em todos os animais, pode-se notar, clinicamente, excelente adaptação à cirurgia e normalidade do uso do membro já radiologicamente pode-se observar formação de calo ósseo e cicatrização da fratura. Histologicamente pode-se observar que ocorreu formação de calo ósseo 15 dias após a cirurgia e cicatrização com remodelação completa a partir dos 90 dias. Nesse exame, além de leve a moderada reação inflamatória no período inicial de avaliação, nenhum outro evento foi notado nos períodos subseqüentes. Concluiu-se que a técnica e os materiais utilizados se tornam uma opção altamente viável na osteossíntese umeral transversa de pombos domésticos.

Palavras-chave: cirurgia, ortopedia, aves, implante ósseo, glicerina.

\section{ABSTRACT}

The objective of the present study was to evaluate the use of a homologous bone intramedullary pin, conserved in glycerin at $98 \%$ associated to hemicerclage with a thread of polyglactina 910 in the transverse humerus osteosynthesis of domestic pigeon (Columba livia). The distal part of the tibialtarsus, conserved with bone marrow, was used as a bone pin. Twenty domestic pigeons were operated, adults, no sex distinction, clinically healthy. Those animals were separated randomly in five groups, with four individuals. The humerus was transversely split up surgically in its diaphysis and the bone pin, properly implanted in the sinus of the bone. Holes were accomplished and through them it was possible to proceed the hemicerclage in Wolff suture form with polyglactina 910. The animals were evaluated clinically through weekly $x$-rays and histologically after periods of 15, 30, 60, 90 and 120 days. The conservation of the bone pin in glycerin at $98 \%$ was evaluated through microbiological exams. In all the animals, clinically can be noticed excellent adaptation concerning the surgery and normality of the use of the member, and radiologically, bone callus formation and cicatrization of the fracture can be observed. Histologically, it is observed bone callus formation 15 days after the surgery and cicatrization with complete remodeling from 90 days. In that exam, besides light to moderate inflammatory reaction in the initial period of evaluation, no other event was diagnosed in the subsequent periods. It was concluded that the technique and used materials become a highly viable option in the humerus transverse osteosynthesis of domestic pigeons.

Key words: surgery, orthopedics, birds, bone implant, glycerin.

\section{INTRODUÇÃO}

Nas aves o esqueleto é formado por ossos leves, de cortical fina, providos de medula óssea ou ocos, com comunicação ou não entre si e com sacos

\footnotetext{
'União de Ensino do Sudoeste do Paraná (UNISEP). Endereço para correspondência: Rua Manoel Ribas, 450, 85504-330, Pato Branco, PR, Brasil. E-mail: jbolsonvet@yahoo.com.br.

"Departamento de Pequenos Animais, Universidade Federal de Santa Maria (UFSM), Santa Maria, RS, Brasil.

IIICurso de Medicina Veterinária, UFSM, Santa Maria, RS, Brasil.
} 
aéreos, e conseqüentemente com o sistema respiratório. Devido a tais características, fica difícil estabelecer um método de estabilização de fraturas que seja eficiente em todos os ossos das aves.

Graças à evolução da medicina, e conseqüentemente das suas especialidades como a ortopedia, encontram-se disponíveis diversos métodos e meios de estabilização de fraturas, que podem ser aplicados aos seres humanos e também aos animais. Deve-se considerar que os dispositivos humanos, para serem utilizados em animais, na maioria das vezes, requerem modificações ou adaptações. Nesse aspecto, a extrapolação dos novos dispositivos de osteossíntese aplicados a humanos é bem utilizada em cães e gatos, porém, fica limitada quando se trata de ortopedia em aves, devido às características peculiares de seu esqueleto.

WHELER (2002) classificou os problemas ortopédicos das aves em duas categorias distintas, a congênita e a traumática. As congênitas, vistas comumente em psitacídeos, e raramente em aves de rapina, e as traumáticas, vistas igualmente nas diversas espécies. Os ossos mais comumente envolvidos nas fraturas são os ossos dos membros pélvicos, das asas e do crânio. As fraturas dos membros pélvicos são mais comuns em aves de gaiola e as lesões de asas ou do crânio são mais comuns em aves de vida livre (WOOD, 1941).

O sucesso da cirurgia ortopédica em qualquer espécie está diretamente relacionado com as técnicas utilizadas para anular as forças mecânicas de uma fratura, controlar a infecção, fazer a manutenção do suprimento sangüíneo e gatantir bom tratamento pós-operatório (BUSH, 1977; WILLIAMS et al. 1987). A maior parte das osteossínteses em aves têm cicatrização por segunda intenção. Isso ocorre porque dificilmente se consegue estabilização rígida (BENNETT, 1997). WEST et al. (1996) estudaram cicatrização óssea em pombos, observando intenso calo fibrocartilaginoso quinze dias após a cirurgia. Esse calo, segundo WILLIAMS et al. (1987), oferece estabilização importante, fundamental no processo de cicatrização.

Os pinos metálicos intramedulares proporcionam excelente resistência a encurvamento, porém, não resistem a forças rotacionais ou carregamento axial (FOSSUM, 2005). A técnica é desestimulada por alguns cirurgiões devido ao grande risco de causar danos articulares e periarticulares, que podem acarretar em anquiloses, prejuízos a tendões ou ligamentos, ocasionando disfunção parcial ou total do membro(MARTIN \& RITCHIE, 1994). BENNETT(1997) citou que na associação de pino intramedular e cerclagem, em pássaros pequenos, os fios de aço podem ser substituídos por fios absorvíveis.
A imobilização externa tipo I isolada é aconselhada em fraturas umerais contaminadas (JACKSON, 1996). Para COLES (1985), nas aves essa técnica é desancoselhada, pois é grande a incidência de não união óssea, secundária à atrofia por desuso. As placas e os parafusos têm seu uso restrito em aves, devido à presença de cortical quebradiça e à baixa resistência principalmente no úmero devido à carga aerodinâmica a que é submetido, principalmente nas aves que voam (LEVITT, 1989).

WANDER et al. (2000) salientaram que técnicas comuns como o pino intramedular e o fixador externo conferem maior morbidade, quando comparadas com implantes ou enxertos intramedulares fixos, devido à necessidade de uma segunda intervenção para remoção dos mesmos.

CUNHA et al. (2004) reduziram fraturas umerais com êmbolos de seringa de um mililitro, associados a hemicerclagem com fio de aço. Eles observaram boa coaptação, cicatrização aos 25 dias, bom alinhamento rotacional, sendo que a prótese pôde permanecer implantada sem complicações. WANDER et al. (2000) promoveram osteossíntese umeral em pombos com xenoenxerto ósseo cortical, preservado por congelamento, como pino intramedular e, apesar de observarem calo ósseo considerável, houve quebra dos enxertos. Já GAIGA (2002) utilizou xenoenxerto ósseo cortical preservado em glicerina a 98\% ou mel e relatou resultados satisfatórios. Segundo PINTO Jr. et al (1995), a glicerina a 98\% é um bom meio de preservação óssea, apresentando baixo custo, fácil obtenção, dispensando materiais ou técnicas especiais. Por outro lado, STEVENSON (1998) alertou sobre a alta antigenicidade dos xenoenxertos que podem resultar em rejeição, retardo ou não união óssea. Para GOLDBERG \& STEVENSON(1987), o material de melhor biocompatibilidade seria o homoenxerto.

Os pinos ou as barras de conexão estão entre os implantes mais popularmente utilizados na ortopedia humana (ROUSH \& McLAUGHLIN, 1999). Nessa técnica, os materiais são inseridos no canal medular e travados em posição com parafusos. Os pinos ou as barras de conexão resistem a todas as forças que atuam em fraturas (FOSSUM, 2005). O objetivo do trabalho foi modificar uma técnica baseada nesses princípios, assim o pino intramedular atua como uma barra de conexão e a hemicerclagem substitui os parafusos que travam a barra no interior do osso, objetivando maior estabilidade nas osteossínteses.

\section{MATERIAL E MÉTODOS}

Para o desenvolvimento da pesquisa foram utilizados 20 pombos domésticos (Columba livia), 
clinicamente sadios, não-sexados, pesando entre 300 e 350 gramas, que foram tratados conforme as normas do Colégio Brasileiro de Experimentação Animal (COBEA). Os animais foram separados aleatoriamente em cinco grupos com quatro componentes, que foram denominados de G15, G30, G60, G90 e G120, sendo que o número que acompanha a letra G identifica a quantidade de dias a serem avaliados.

Os tibiotarsos homólogos foram coletados de animais clinicamente sadios, preparados e acondicionados aos pares, imersos em glicerina a 98\%. Para a cirurgia, as aves foram submetidas a jejum alimentar de duas horas, sem jejum hídrico. Amedicação pré-anestésica foi efetuada com cloridrato de cetamina, na dose de $30 \mathrm{mg} \mathrm{kg}^{-1}$, associada a butorfanol, na dose de $2 \mathrm{mg} \mathrm{kg}^{-1}$. Enrofloxacina na dose de $20 \mathrm{mg} \mathrm{kg}^{-1}$ foi utilizada para a profilaxia bacteriana. Vinte minutos antes do procedimento administrou-se flunixim meglumine, na dose de $2 \mathrm{mg} \mathrm{kg}^{-1}$. A indução anestésica, com máscara e manutenção, via sonda endotraqueal foi efetuada com isofluorano. O decúbito foi o lateral direito e foi realizada a antissepsia com álcool 70\% e iodo a $1 \%$.

Acessou-se o úmero dorso-lateralmente, após efetuou-se osteotomia diafisária transversa completa, com broca odontológica, sob irrigação. O pino ósseo foi parcialmente introduzido no seio do coto proximal e, após distração e angulação, encaixou-se o restante do pino no seio do coto distal (Figura 1A). Após redução da fratura, dois orifícios foram realizados, um em cada coto, a uma distância de meio centímetro da linha de fratura. Através desses orifícios, passouse o fio sintético e efetuou-se o nó, apertando o conjunto formado pelo úmero/pino ósseo (Figura 1B). A hemicerclagem resultante tem a configuração de um ponto de Wolff. Em seguida, a área foi lavada e o acesso fechado como de rotina. O pós-operatório consistiu de limpeza e administração de flunexim meglumine na mesma dose pré-operatória, duas vezes ao dia por dois dias.

A avaliação clínica diária consistia na verificação da saúde geral e no exame ortopédico da asa operada. A avaliação radiológica foi efetuada imediatamente (Figura 1C) e em períodos semanais após a cirurgia. Para os exames histológicos, os ossos foram descalcificados, fixados em parafina, seccionados por micrótomo e corados com a técnica de Hematoxilina Eosina (HE). A análise bacteriológica da conservação em glicerina a $98 \%$ foi realizada por meio de cultura.

\section{RESULTADOS}

O protocolo anestésico, analgésico, antiinflamatório e antimicrobiano utilizado mostrou-se eficaz, visto que os procedimentos cirúrgicos foram efetuados de forma tranqüila, sem manifestação de dor trans e pós-operatória e sem sinais de inflamação e infecção. O acesso cirúrgico utilizado proporcionou boa visualização, fácil manipulação e possibilidade da execução, sem dificuldades, das manobras de osteotomia, introdução do pino ósseo, distração, angulação, redução da fratura e execução da hemicerclagem.

Clinicamente não ocorreram problemas de saúde geral. Na avaliação ortopédica da asa operada, pôde ser notada, por palpação, a partir dos 15 dias de pós-operatório, a presença de calo na diáfise umeral dos animais operados. A partir dos 60 dias, pôde-se observar significativa diminuição no calo ósseo e ausência dos mesmos a partir dos 90 dias. Nenhum movimento na linha de fratura foi observado em qualquer período de avaliação.

Radiograficamente os animais do grupo G15 não apresentavam linha de fratura, indicando cicatrização em período de 15 dias. Existiu presença de calo ósseo em todos os participantes do experimento e sua intensidade foi mais evidente no período de 30 dias (Figura 1D), significativa diminuição nos períodos superiores a 60 dias e ausência a partir dos 90 dias de pós-operatório (Figura 1E). Considerou-se, portanto, remodelação a partir dos 90 dias.

Reações inflamatórias graves foram observadas histologicamente nas amostras dos animais do grupo G15 e em um animal do grupo G30. Essa reação inflamatória foi constituída predominantemente por células gigantes multinucleadas e alguns eosinófilos (Figura 1F). Em um animal do grupo G15, observou-se presença de macrófagos. Nos outros três animais do grupo G30 e em um animal do grupo G60, observou-se reação inflamatória leve com presença predominante de células monomorfonucleares. Nos outros três animais do grupo G60 não foram observados quaisquer sinais inflamatórios. Nos outros oito animais pertencentes aos grupos G90 e G120, também não foi detectado sinal de inflamação. Foi detectada a presença de fibrina nos quatro animais do grupo G15, em três animais do grupo G30 e em um animal do grupo G60. A deposição de fibrina foi severa nos animais do grupo G15 e moderada nos demais animais que apresentaram esse evento.

Proliferação de tecido de granulação foi observada em todos os animais do grupo G15, em dois animais do grupo G30 e em um animal do grupo G60. A intensidade da proliferação do tecido de granulação nos animais do grupo G15 foi classificada como grave, nos animais do grupo G30 foi moderada e no animal do grupo G60 foi leve. Em nenhum animal do experimento 


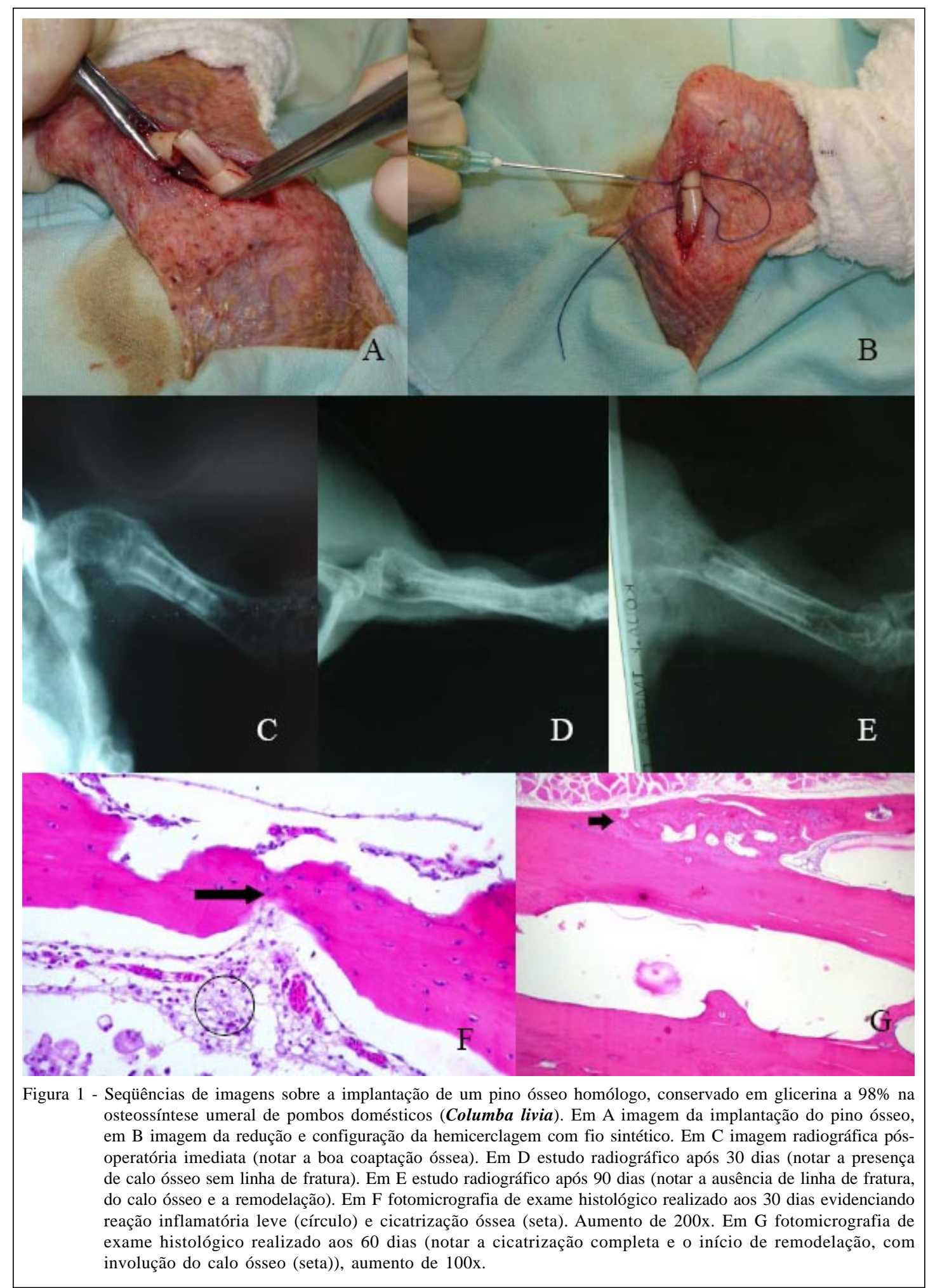

foram detectados sinais de fibrose (tecido conjuntivo fibroso).

Na análise da cicatrização óssea, os animais do grupo G15 apresentaram cicatrização moderada com presença de calo ósseo; os animais do grupo G30 apresentaram cicatrização completa com presença de calo ósseo. Os animais do grupo G60 também apresentaram intensa cicatrização óssea com início de

Ciência Rural, v.38, n.7, out, 2008. 
involução do calo ósseo. Os animais dos grupos G90 apresentaram cicatrização completa com involução do calo ósseo e remodelação (Figura $1 \mathrm{G}$ ) e as aves do grupo G120 intensa cicatrização e total remodelação.

A glicerina a 98\% conservou o implante sem contaminação. Os exames bacteriológicos dos ossos conservados tiveram o laudo com resultados negativos para bactérias aeróbias e anaeróbias.

\section{DISCUSSÃO}

O protocolo anestésico permitiu a realização dos procedimentos sem inconvenientes. A cetamina também foi utilizada por BOLSON et al. (2004) e CASTRO et al. (2004) como fármaco indutor em aves e o isofluorano já foi considerado o fármaco mais seguro para indução e manutenção da anestesia inalatória nas aves (COLES, 1985; STEINER \& DAVIS, 1985; BOLSON 2005).

O uso de antiinflamatórios é indicado em qualquer procedimento cirúrgico em aves (MARCHIN, 2002). Nesse experimento utilizou-se a administração preemptiva, como indicam FANTONI \& MASTROCINQUE (2004), de flunexim meglumine, não observando-se sinal clínico de inflamação. Para analgesia, utilizou-se o butorfanol, não ocorrendo sinais clínicos de dor, corroborando o estudo de FREITAS et al. (2003), que utilizaram o fármaco após osteossíntese umeral em ema (Rhea americana).

Segundo WESTFALL \& EGGER (1979), deve-se oferecer cobertura antimicrobiana quando se faz uso de qualquer material implantado. A enrofloxacina na dose utilizada preveniu sinais de infecção, conforme observado previamente na mesma espécie por LEOTTE (2003) e DALMOLIN (2006).

$\mathrm{O}$ acesso ao úmero utilizado nesse experimento foi também utilizado por BOLSON et al. (2004), CUNHA et al. (2004), TEIXEIRA et al. (2004), BOLSON et al. (2006), DALMOLIN (2006) para úmero de pombos domésticos (Columba livia). Diferentemente, GAIGA (2002) utilizou acesso ventral, porém, para BAUMEL (1986), esse acesso é arriscado, pois encontra na sua trajetória a artéria braquial.

A técnica cirúrgica foi fundamentada na aplicação de barra intramedular travada, como indicou FOSSUM (2005), na qual o pino ósseo atua como a barra intramedular, anulando as forças de flexão e a hemicerclagem ocupa o lugar dos parafusos travando as forças de rotação e distração. Nesse experimento, o pino ósseo e o fio ofereceram estabilidade apropriada atuando como eficientes dispositivos de osteossíntese. Segundo BENNETT (1997), os fios de aço cirúrgico podem ser substituídos por fios de sutura absorvíveis em pássaros pequenos. CUNHA et al. (2004), associaram pino intramedular de polipropileno com hemicerclagem de fio de aço, e foram obtidos bons resultados. TEIXEIRA et al. (2004) realizaram a mesma técnica, porém, sem cerclagem, mas com bandagem externa, imobilizando a asa contra o corpo, mas observando falha de cicatrização em $30 \%$ das aves operadas.

Na avaliação clínica, foram observados movimentos normais do membro e sua posição anatômica, logo após a cirurgia. Para LEVITT (1989), o método de fixação deve permitir o uso normal do membro no pós-operatório, pois pequenos movimentos minimizam a atrofia e ajudam a cicatrização. Os primeiros sinais clínicos de cicatrização da fratura foram detectados aos quinze dias. Nesse exame pode-se palpar imobilidade local e presença de calo. Nas análises radiográficas, aos 15 dias detectou-se também discreta presença de calo, o que discorda das informações prestadas por WILLIAMS et al. (1987) e WISSMAN (1999) de que os sinais radiográficos de consolidação óssea ocorrem mais tardiamente que os sinais clínicos. Aos 21 dias de pós-operatório, por meio de radiografias, observou-se presença marcante de calo ósseo, corroborando o estudo de CUNHA et al. (2004). Já GAIGA (2002) observou cicatrização aos 35 dias em osteossíntese umeral de pombos utilizando como pino intramedular tíbia ou fíbula de cães conservadas em glicerina ou no mel. BOLSON et al. (2005) e DALMOLIN (2006) utilizaram combinação de pino intramedular estabilizado por barra acrílica a um pino transverso e conseguiram sinais radiográficos de cicatrização após 22 dias da cirurgia. LEOTTE (2003) observou radiograficamente cicatrização aos 28 dias de pósoperatório, após osteossíntese umeral em pombos com transfixação externa do tipo I.

Confrontando o resultado desses experimentos, o tempo para observação dos primeiros sinais radiográficos de cicatrização de uma fratura umeral, corrigida cirurgicamente, é de aproximadamente 25 dias. Observou-se que a diferença entre os procedimentos recaiu sobre os materiais usados para osteossíntese umeral. Notou-se que o tempo de cicatrização mais demorado foi observado por GAIGA (2002). Isso pode ser devido ao fato de o autor ter utilizado xenoenxerto ósseo, que, entre os materiais nesse contexto confrontados, é o que apresenta maiores reações antigênicas. Portanto, pode-se sugerir que o nível de antigenicidade de um implante é fator relevante no tempo de cicatrização óssea.

$\mathrm{Na}$ avaliação histológica dos animais do grupo G15, detectou-se calo ósseo-cartilaginoso. Segundo ALLEN et al. (1980), essa fase da cicatrização 
é chamada de fase osteogênica. NEWTON \& ZEITLIN (1977) observaram cicatrização de fratura do rádio em três semanas, quando rigidamente fixadas. WEST et al. (1996) também relataram a formação de calo cartilaginoso em aves, após 15 dias da osteossíntese.

Aos 30 dias de avaliação clínica, pôde-se palpar significante presença de consistência compatível com calo ósseo, que foi confirmado por meio de radiografias. Histologicamente foi detectada moderada reação inflamatória em meio a considerável deposição de fibrina e tecido de granulação. Segundo ALLEN et al. (1980), essa fase de cicatrização pode ser chamada de fase de ossificação ou então cicatrização de grau 3.

Aos 60 dias, clinicamente palpava-se calo ósseo mais discreto que aos 30 dias, sugerindo início de involução do calo que foi confirmado radiologicamente. Histologicamente constatou-se ausência de sinais de inflamação, cicatrização e início de remodelação. Aos 90 e 120 dias de pós-operatório, não se palpou calo ósseo e radiologicamente foi observada cicatrização completa e ausência de calo ósseo, sugerindo remodelação. Histologicamente, detectou-se cicatrização completa com involução do calo ósseo e remodelação óssea. A cicatrização óssea dos animais ocorreu por segunda intenção, segundo BROWN \& KRAMERS (1996). Essas fraturas são assim classificadas porque cicatrizam com algum tecido interposto entre os cotos ósseos. Assim, a osteossíntese estudada oferece excelente imobilização, porém, não oferece estabilidade com 100\% de rigidez.

Pelos exames histológicos pôde-se observar que o tecido de granulação e, por conseguinte, o calo cartilaginoso e ósseo tiveram início tanto no endósteo quanto no periósteo e também em tecidos conectivos, da mesma forma que foi citado por NEWTON \& ZEITLIN (1977). Nesse experimento não se mensurou a quantidade de calo formado no endósteo e periósteo. No entanto, WEST et al. (1996) em estudo histológico, em pombos, notaram que a formação de calo ósseo periosteal é mais exuberante que a formação de calo endosteal.

Os animais desse experimento só foram submetidos a teste de vôo depois do empenamento completo que foi notado 40 dias após a cirurgia. Quando soltos ao vôo, todos eles voaram e foram avaliados como normais, exaltando o resultado positivo da técnica proposta. CUNHA et al. (2004) observaram vôo normal já aos 21 dias após osteossíntese umeral. Porém, STEINER \& DAVIS (1985) oferecem dados fisiológicos de que as penas arrancadas com o folículo só voltam a crescer e retomam o seu tamanho normal dentro de cinco a dez semanas. Com base nessas discrepâncias, sugerem-se estudos de avaliação clínica do tempo de retorno ao vôo, após cirurgias sem a remoção das penas.

Utilizou-se a glicerina a $98 \%$ como meio conservante seguindo as orientações de PINTO Jr. et al. (1995) e GOLDBERG \& STEVENSON (1987) e ela mostrou-se eficaz para o propósito que foi utilizada.

\section{CONCLUSÃO}

Com base nos resultados obtidos com o desenvolvimento desse experimento, é possível concluir que o implante de um pino ósseo homólogo conservado em glicerina a $98 \%$, associado a hemicerclagem com fio poliglactina 910 em forma de pontos de Wolff, é uma opção altamente viável na osteossíntese umeral transversa de pombos domésticos. O material implantado apresenta baixa antigenicidade, excelente anulação de forças que agem numa fratura e não necessita remoção após sua atuação.

\section{AGRADECIMENTOS E APRESENTAÇÃO}

A minha esposa, Roberta Bolson, e meus filhos Julia Bolson e Miguel Bolson. A todos os funcionários do hospital veterinário, professores do curso de Medicina Veterinária e do Programa de Pós-graduação em medicina Veterinária (PPGMV) da UFSM.

Parte da Tese de Doutorado do primeiro autor apresentada ao Programa de Pós-graduação em Medicina Veterinária da UFSM, como requisito parcial para obtenção do título de Doutor em Medicina Veterinaria - subárea cirurgia.

\section{COMITÊ DE ÉTICA}

Esta pesquisa foi desenvolvida antes da formação do comitê de ética em pesquisas com animais da UFSM.

\section{REFERÊNCIAS}

ALLEN et al. Indomethacin and aspirin: efect of nonsteriodal antiinflammatory agentes on the fracture repair in rat. Acta Orthopaedica Scandinavia, v.51, p.595-600, 1980.

BAUMEL, J.J. Coração e vasos sanguíneos das aves. In: GETTY, R. Anatomia dos animais domésticos. 5.ed. Rio de Janeiro: Guanabara Koogan, 1986. Cap.67, p.1843-1880.

BENNETT, R.A. Orthopedic surgery. In: ALTMAN, R.B. et al. Avian medicine and surgery. Philadelphia: Saunders, 1997. p.733-766.

BOLSON, J. et al. Substituição de segmento ósseo umeral em pombos (Columba livia) por prótese confeccionada a partir do polímero de mamona (Ricinnus communis) - dados parciais. In: SIMPÓSIO GAÚCHO SOBRE ANIMAIS SELVAGENS, 2004, Santa Maria, RS. Anais... Santa Maria: Pró-reitoria de Pós-graduação e Pesquisa, 2004. 1CD.

BOLSON, J. Comportamento do polímero de mamona (Ricinnus communis) em ossos de codornas domésticas (Coturnix japonica). 2005. 57f. Dissertação (Mestrado em cirurgia) - Programa de Pós-graduação em Medicina Veterinária, Universidade Federal de Santa Maria. 
BOLSON, J. et al. Osteossíntese umeral em pombos (Columba livia) com a utilização de pino intramedular estabilizado externamente por barra acrílica. In: CONGRESSO BRASILEIRO DA ANCLIVEPA, 26., 2005, Salvador, BA. Anais... Salvador: ANCLIVEPA, 2005. 1CD.

BOLSON, J. et al. Osteossíntese umeral em pombos domésticos (Columba livia) com pino intramedular de polímero de mamona (Ricinnus communis) e hemicerclagem com fio poliglactina 910 no padrão Wolf. In: JAI - Jornada acadêmica integrada da UFSM, 20., 2006, Santa Maria, RS. Anais... Santa Maria: Pró-Reitoria de Pós-Graduação e Pesquisa, 2006. 1CD.

BROWN, S.G.; KRAMERS, P.C. Consolidação óssea indireta (secundária). In: BOJRAB, M.J. Mecanismos da moléstia na cirurgia dos pequenos animais. 2.ed. São Paulo: Manole, 1996. Cap.97, p.783-790.

BUSH, M. External fixation of avian fractures. Journal of the American Veterinary Medical association, v.171, n.9, p.943-946, 1977

CASTRO, P.F. et al. Uso de pino de aço intramedular na reparação de fraturas de ossos longos em psitacídeos: arara-azul (Anodorhynchus hyacinthinus), arara-canindé (Ara ararauna) e papagaio-verdadeiro (Amazona aestiva). Clínica Veterinária, ano. IX, n.52, p.56-64, 2004.

COLES, B.H. Surgery. In: Avian medicine and surgery. Philadelphia: Blackwell Scientific Publications, 1985. Cap.6, p.148-154.

CUNHA, O. et al. Osteossíntese de úmero com êmbolo de seringa em pombos domésticos. Medvep - Revista Científica de Medicina Veterinária - Pequenos Animais e Animais de Estimação, v.2, n.6, p.87-90, 2004.

DALMOLIN, F. Modificações do fixador externo para osteossíntese umeral em pombos domésticos (Columba livia). 2006. 33f. Dissertação (Mestrado em cirurgia), Programa de Pós-graduação em Medicina Veterinária, Universidade Federal de Santa Maria.

FANTONI, D.T.; MASTROCINQUE, S. Analgesia preemptiva: mito ou fato? Clínica Veterinária, ano IX, n.49, p.24-32, 2004.

FOSSUM, T.W. Cirurgia de pequenos animais. São Paulo: Roca, 2005. 1390p.

FREITAS, S.H. et al. Redução fechada e fixador externo em fratura umeral de ema (Rhea americana) - Relato de caso. Clínica Veterinária, ano VIII, n.45, p.40-42, 2003.

GAIGA, L.H. Osteossíntese de úmero por xenoenxerto ósseo preservado em glicerina a $98 \%$ ou mel em pombos domésticos (Columba livia). 2002. 45f. Dissertação (Mestrado em Cirurgia) - Programa de Pós-graduação em Medicina Veterinária (PPGMV), Universidade Federal de Santa Maria.

GOLDBERG, V.; STEVENSON, S. Natural history of autografts and allografts. Clinical orthopedics and related research, n.225, p.7-16, 1987

JACKSON, D.A. Tratamento das fraturas umerais. In: BOJRAB, M.J. Técnicas atuais em cirurgia de pequenos animais. São Paulo: Roca, 1996. Cap.47, p.710-724.

LEOTTE, A.M. Fixação esquelética tipo I para osteossíntese diafisária de úmero e resposta inflamatória em pombos domésticos (Columba livia). 2003. $42 \mathrm{f}$. Dissertação (Mestrado em cirurgia) - Programa de Pósgraduação em Medicina Veterinária, Universidade Federal de Santa Maria

LEVITT, L. Avian orthopedics: Compendium on Continuing Education for the Practicing Veterinarian, v.11, n.8, p.899-929, 1989.

MARCHIN, K.L. Assessment of the analgesic effects of ketoprofen in ducks anesthetized with isoflurane. American Journal of Veterinary Research, v.63, n.6, p.821-826, 2002.

MARTIN, H.; RITCHIE, B.W. Orthopedic surgical techniques. In: RITCHIE, B.W. et al. Avian medicine: principles and application. Lake Worth: Wingers, 1994. p.1137-1169.

NEWTON, C.D.; ZEITLIN, S. Avian fracture healing. Journal of the American Veterinary Medical Association, v.170, n.6, p.620-625, 1977 .

PINTO JR., H.S. Utilização de enxerto ósseo cortical homólogo preservado em tintura de iodo a $2 \%$ na reparação de fraturas cominutivas de ossos longos de cães. 1995. 75f. Tese (Doutorado em Medicina Veterinária) - Universidade de São Paulo.

ROUSH, J.K.; McLAUGHLIN, R.M. Using interlocking nail fixation to repair fractures in small animals. Veterinary Medicine, v.94, n.1, p.46-52, 1999.

STEINER, C.V.; DAVIS, R.B. Patologia de las aves enjauladas. Zaragoza: Acribia, 1985. 165p.

STEVENSON, S. Enxertos ósseos. In: SLATTER, D. Manual de cirurgia de pequenos animais. 2.ed. São Paulo: Manole, 1998. V.2, cap.127, p.2006-2017.

TEIXEIRA. C.R. et al. Haste intramedular de polipropileno, combinada ou não a biomateriais, no tratamento de fraturas induzidas no úmero de pombos. Archives of Veterinary Science, v.9, n.1, p.67-72, 2004

WANDER, K.M. et al. Fracture healing after stabilization with intramedulary xenograft cortical bone pins: a study in pigeons. Veterinary Surgery, v.39, p.237-244, 2000.

WHELER, C.L. Orthopedic conditions of the avian head. Veterinary Clinics of North América: Exotic Animals Practice, v.5, n.1, p.83-95, 2002.

WEST, P.G. et al. Histomorphometric and angiographic analysis of bone healing in the humerus of pigeons. American Journal of Veterinary Research, v.57, p.1010-1015, 1996.

WESTFALL, M.L.; EGGER, L.E. The management of long bone fractures in birds. Iowa State Veterinarian, v.41, n.2, p.81-87, 1979.

WILLIAMS, R. et al. A comparative study of treatment methods for long bone fractures. Companion Animal Practice, v.1, n.4, p.48-55, 1987.

WISSMAN, M.A. New tools, diagnostics aid in bone and beak repair in birds. Veterinary Product News, v.11, n.6, p.4445, 1999.

WOOD, H.B. Fractures among birds. Bird-Banding, v.12, p.68-72, 1941 . 